\title{
Impact of Consultant Obstetric Presence on Serious Incidents.
}

DOI:

10.1108/IJHG-12-2018-0079

\section{Document Version}

Accepted author manuscript

Link to publication record in Manchester Research Explorer

\section{Citation for published version (APA):}

Shawer, S., Rowbotham, S., Heazell, A., Kelly, T., \& Vause, S. (2019). Impact of Consultant Obstetric Presence on Serious Incidents. International Journal of Health Governance. https://doi.org/10.1108//JHG-12-2018-0079

\section{Published in:}

International Journal of Health Governance

\section{Citing this paper}

Please note that where the full-text provided on Manchester Research Explorer is the Author Accepted Manuscript or Proof version this may differ from the final Published version. If citing, it is advised that you check and use the publisher's definitive version.

\section{General rights}

Copyright and moral rights for the publications made accessible in the Research Explorer are retained by the authors and/or other copyright owners and it is a condition of accessing publications that users recognise and abide by the legal requirements associated with these rights.

\section{Takedown policy}

If you believe that this document breaches copyright please refer to the University of Manchester's Takedown Procedures [http://man.ac.uk/04Y6Bo] or contact uml.scholarlycommunications@manchester.ac.uk providing relevant details, so we can investigate your claim.

\section{OPEN ACCESS}




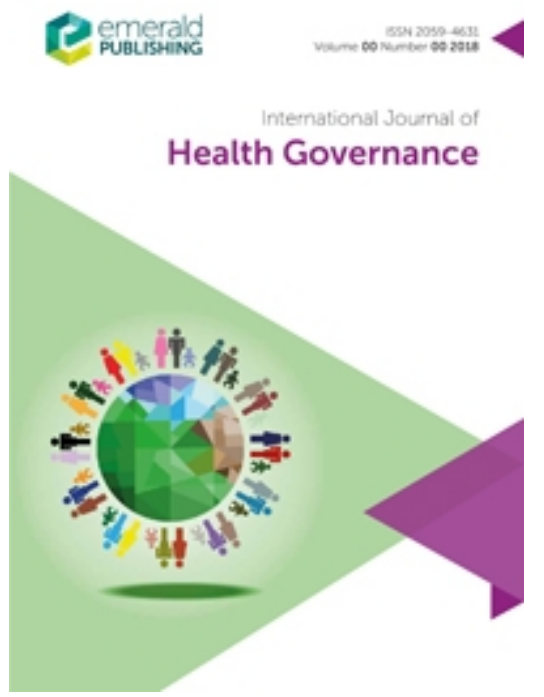

\section{Impact of Consultant Obstetric Presence on Serious Incidents.}

\begin{tabular}{|r|l|}
\hline Journal: & International Journal of Health Governance \\
\hline Manuscript ID & ijhg-12-2018-0079.R1 \\
\hline Manuscript Type: & Original Article \\
\hline Keywords: & $\begin{array}{l}\text { Obstetrics < Health Professions, Adverse events or outcomes < Health } \\
\text { Service Quality Assurance, Patient safety < Health Service Quality } \\
\text { Assurance, Midwifery < Health Professions, Clinical effectiveness < } \\
\text { Health Service Quality Assurance, Teamwork < Health Service Quality } \\
\text { Assurance }\end{array}$ \\
\hline
\end{tabular}

\section{SCHOLARONE \\ Manuscripts}


Impact of Consultant Obstetric Presence on Serious Incidents.

\begin{abstract}
Purpose - Many organisations, including the Royal College of Obstetricians and Gynaecologists, have recommended increasing the number of hours of consultant obstetric presence in UK National Health Service maternity units to improve patient care. St Mary's Hospital, Manchester implemented 24-7 consultant presence in September 2014.

Design/Methodology - To assess the impact of 24-7 consultant presence upon women and babies, a retrospective review of all serious clinical intrapartum incidents occurring between September 2011 and September 2017 was carried out by two independent reviewers; disagreements in classification were reviewed by a senior Obstetrician. The impact of consultant presence was classified in a structure agreed $a$ priori.
\end{abstract}

Findings - A total of 72 incidents were reviewed. Consultants were directly involved in the care of $75.6 \%$ of cases before $24-7$ consultant presence compared to $96.8 \%$ afterwards. Negative impact due to a lack of consultant presence fell from $22 \%$ of the incidents before 24-7 consultant presence to $9.7 \%$ after implementation. In contrast, positive impact of consultant presence increased from $14.6 \%$ to $32.3 \%$ following the introduction of $24-7$ consultant presence.

Practical Implications - Introduction of 24-7 consultant presence reduced the negative impact caused by a lack of, or delay in, consultant presence as identified by serious untoward incident reviews. Consultant presence was more likely to have a positive influence on care delivery.

Originality/Value - This is the first assessment of the impact of 24-7 consultant presence on the serious untoward incidents in obstetrics.

Keywords: Obstetrics, Midwifery, Adverse events or outcomes, Patient safety, Clinical effectiveness, Teamwork

Paper type: Case study 


\section{Introduction}

Since 2005, national UK-based organisations including the National Health Service Litigation Authority (NHSLA) and Royal College of Obstetricians and Gynaecologists (RCOG) have recommended increasing consultant obstetrician (the most senior clinicians) presence in UK consultant-led maternity units to provide improved care for mothers and babies (Royal College of Obstetricians and Gynaecologists, 2005; National Health Service Litigation Authority, 2013; Royal College of Obstetricians and Gynaecologists, 2016). In part, this recommendation is driven by a desire to reduce avoidable harm and to improve the quality of care. There is also an economic imperative as in $2016 / 17$, successful litigation claims for adverse maternity outcomes amounted to $>£ 2 B N$, representing $50 \%$ of the total claims cost despite only representing $10 \%$ of the total number of claims (National Health Service Resolution, 2017). Thus, a reduction in avoidable harm could have significant economic benefits. However, few studies have attempted to examine the association between the amount of consultant obstetric presence in a maternity unit and Serious Untoward Incidents (SUIs). A recent debate highlighted the degree of controversy among clinicians and the academic community regarding the impact of 24-7 consultant presence (Walker, 2016; Snowden et al., 2016; Smith, 2016; Roach, 2016). A subsequently published meta-analysis concluded that although the current evidence regarding the impact of consultant presence is of low quality, there may be evidence of beneficial effects (reduced Caesarean deliveries and a greater proportion of spontaneous vaginal births); this review concluded that further evaluation is needed, particularly to evaluate the effect on rare but serious outcomes (Henderson et al., 2017).

In September 2014, St Mary's Hospital, Manchester became one of the first maternity units in the UK to provide 24-7 consultant presence, where consultant obstetricians are present at 
all times of day or night, to lead the team and make decisions about patient care; consultant presence followed a pattern of week day shifts (usually $8.30-17: 00$ and then 17:00-20:30) and a single night shift (20:30-08:30) and of two 12-hours shifts per weekend (08:30-20:30 and 20:30-08:30). An analysis of the impact of 24-7 consultant presence on patient care was planned following implementation of 24-7 consultant presence to provide a holistic evaluation of the effectiveness of 24-7 consultant presence and whether it impacts upon the safety and experience of care provided for women and their babies (Reid et al., 2018). This component of the evaluation aimed to determine whether 24-7 consultant presence altered the clinical outcomes reviewed in SUIs.

\section{Methods}

All obstetric intrapartum clinical incidents which reported a severity level of "severe" or "catastrophic" (i.e. SUIs) using the National Patient Safety Agency instrument (National Patient Safety Agency, 2008) at Saint Mary's Hospital, Manchester, occurring between September 2011 and September 2017 were identified from the Trust's electronic (Ulysses) incident reporting system. During the time period the type and nature of intrapartum incidents to be reported were publicised to all clinical staff and regular practice reviews were conducted. We excluded non-clinical incidents and incidents exclusively involving antenatal care, elective operations, or midwifery-led care as 24-7 consultant obstetric presence would not have been likely to impact upon these events. A retrospective review of the included incident investigation reports was carried out independently by two investigators (SS and SR). The findings of SUIs were classified into mutually exclusive categories describing the consultant involvement and impact on the care provided; these categories were developed $a$ priori to avoid bias (Figure 1). Contributory factors identified in the incident investigation reports were collated and categorised to identify recurring themes. Disagreements in 
classification were arbitrated by a senior Obstetrician (TK). The cases were then divided into those which occurred 'before' and those that were 'after' introduction of 24-7 consultant presence. Statistical analysis was undertaken using STATA (Version 13, Statacorp, TX, USA).

\section{Results}

A total of 53,726 births took place at St Mary's Hospital between September 2011 and September 2017; 25,641 births before and 28,085 after the implementation of the 24-7 consultant presence. The patient-safety incidents reported to National Reporting and Learning System (NRLS) before the 24-7 consultant presence were 6,260 in total, 41 of which met our inclusion criteria. After the 24-7 consultant presence was implemented, 7,881 incidents were reported to the NRLS, 31 of which met our inclusion criteria; thus, the proportion of SUls was not statistically significantly different between the time periods (0.63\% vs. $0.39 \% ; p=0.25$; Chi-squared test). Similarly, catastrophic (Level 5) incidents accounted for $19.5 \%$ of the total number of the reviewed incidents before implementing $24-$ 7 consultant presence, as opposed to $29.0 \%$ of those which occurred afterwards $(p=0.40$, Fisher's Exact Test). The ratio between severe and catastrophic incidents in each time period was unaltered.

Consultants were involved in more of the cases reviewed after 24-7 consultant presence; 30 cases $(96.8 \%)$ compared to 31 cases $(75.6 \%)$ beforehand $(p=0.02)$. The impact of consultant presence also differed following the introduction of 24-7 consultant presence. A reported negative impact due to a lack of consultant presence fell from $22 \%$ of the incidents before 24-7 consultant presence to $9.7 \%$ afterwards. Negative impacts due to a lack of consultant presence included: patients not being reviewed by a consultant during the evening and night ward rounds, misinterpretation of fetal heart rate traces leading to adverse neonatal outcomes, as well as late involvement of consultants in managing post-partum 
haemorrhage. In contrast, positive impact of consultant presence increased from $14.6 \%$ to $32.3 \%$ following the introduction of 24-7 consultant presence (Figure 1). In contrast, the reviewers identified that consultant presence had a negative impact on the management of three incidents; one before and two after implementing the 24-7 consultant presence. For instance, a consultant might persist with a vaginal or instrumental delivery while a more junior doctor would have performed a caesarean section earlier. Before 24-7 consultant presence, the on-call consultant was called in from home to attend in 6 incidents (14.6\%). A negative impact due to lack of or delay in consultant presence was identified in half of these incidents.

A number of other contributory factors were identified in these SUls. 'Staffing levels and capacity' was identified as a contributory factor in 10 incidents, which was evenly distributed between the before and after groups. Failure to follow the unit clinical guidelines contributed to a total of 24 incidents; 15 of which happened before the $24-7$ consultant presence, while 9 happened afterwards ( $p=0.61$, Fisher's Exact Test). Miscommunication was identified in 10 incidents in the 'Before' group, compared to 9 incidents in the 'After' group. Failure to seek support and access senior advice contributed to 5 incidents before the introduction of 24-7 consultant presence and 3 incidents afterwards.

\section{Discussion}

Over time, the Consultant Obstetricians' role in the UK has changed. Currently, the consultant should lead the multidisciplinary team ensuring appropriate and woman-centred care (Royal College of Obstetricians and Gynaecologists, 2005). It has been postulated that their clinical experience, leadership, and proactive management should reduce the risk of adverse outcomes for mothers and babies (Royal College of Obstetricians and 
Gynaecologists, 2007). However, in obstetrics not all serious incidents can be anticipated, and in these situations, the consultant's skills may be directed at secondary prevention of harm rather than primary prevention of the event itself e.g. reduction of blood loss from a postpartum haemorrhage. This study reviewed SUIs relating to intrapartum care and found a reduction in the number of reports where a lack of consultant presence was implicated and an increase in the number of reviews where a consultant had a positive effect.

After a number of individual reports in Germany, Sweden, Switzerland, and Wales showed variation in perinatal outcomes depending on the timing of the birth (Stewart et al., 1998; Luo and Karlberg, 2001; Heller et al., 2000; Ruffieux et al., 1992), a link between consultant obstetric presence and outcome was proposed and 24-7 resident consultant presence was advocated. Data from a Scottish study in 2010 by Pasupathy et al (Pasupathy et al., 2010) reported increased neonatal mortality for out-of-hours delivery, but could not establish causal pathways leading to the observed association. Importantly, the time of delivery or the incident itself does not always relate to the time of clinical error or system failure. For instance, intrapartum fetal hypoxia may be preceded by a period of CTG misinterpretation or missed clinical signs. We have, therefore, assessed the impact of consultant presence on the management of the SUIs and have not adjusted for the time of delivery.

Our study identified an increase in consultant involvement in the patient care in the most serious cases after implementing the $24-7$ consultant presence. Overall, consultant presence had a positive influence on the management of the incidents reviewed, but in part because there were many other contributing factors in the SUIs, 24-7 consultant presence did not prevent all adverse outcomes occurring. Indeed, a lack of consultant presence was still identified in approximately $10 \%$ of reviews following the introduction of $24-7$ consultant presence which may reflect two simultaneous incidents only one of which the consultant 
could directly manage. Nevertheless, there is a significant decline in adverse outcomes relating to lack of, or delay in, consultant presence after implementing the 24-7 consultant presence. The majority of these incidents included unexpected admission to the neonatal intensive care unit, misinterpretation of fetal heart rate traces, and delay in diagnosing and managing PPH with delay in consultant involvement where the advanced clinical and surgical skills of the consultant could have changed the clinical outcome. McNamara et al (McNamara et al., 2018b) reported intrapartum asphyxia, which is potentially preventable with earlier detection and intervention, to account for almost $10 \%$ of intrapartum fetal deaths in Ireland between 2011 and 2014.

SUIs carry a devastating and possibly life-long impact on babies, mothers, and families. The emotional burden on families dealing with intrapartum asphyxia and its complication ranging from minor injuries to cerebral palsy, intrapartum fetal death, and neonatal death cannot be understated. The emotional impact on obstetricians and midwives is also significant and can be long-lasting (McNamara et al., 2018a). SUIs carry an equally profound impact on the NHS in the form of rising cost of claims (National Health Service Letigation Authority, 2013). Thus, a reduction in avoidable harm and the consequent reduction in SUIs is a desirable aim for maternity services.

At present, it is not possible to determine whether the reduction in SUls will translate into a decline in the number and value of litigation claims, as they are usually made several years after intrapartum incidents. Critically, any reduction in costs of litigation would make resident consultant presence much more cost-effective. Currently unfilled obstetric posts, i.e. rota gaps, pose a risk to safety in many UK maternity units and resident consultant posts have been introduced to mitigate this risk. Such posts need to be developed in line with the RCOG's 2016 'Providing Quality Care' report, but may provide added value by bringing 
experience and leadership, rather than simply filling a rota gap (Royal College of Obstetricians and Gynaecologists, 2016).

The difficulty in accurately quantifying the effect of consultant presence is partly due to the fact that obstetricians are only a single member in a multidisciplinary team including; anaesthetists, midwives, and neonatologists. SUls are rarely the result of a single causative factor, and more often show a series of system and person failures as described in the Swisscheese model (Reason, 2000). In addition, one cannot discount whether some of the effect of consultant presence is from an additional staff member, rather than from the additional benefit of experience and leadership. Furthermore, the introduction of 24-7 consultant presence is not the only development within this unit over the time frame of this analysis. These co-existing factors makes it challenging to specifically quantify the impact of the consultant presence on the number of incidents alone, hence, the adopted methodology of isolating and assessing the impact made by the consultant presence on the management of the SUIs.

The retrospective nature of our study could create an element of subjectivity. It was, therefore, planned for all incidents to be reviewed independently by two reviewers to limit potential bias. One limitation of the study was that the implementation of the 24-7 consultant presence model was a gradual process that was completed in September 2014, so there were many occasions where the consultant was resident on the unit out of hours prior to September 2014, or where a non-resident consultant was already available in the unit. Our categorisation of the incidents is based on reviewing the incident investigation reports, while the patients' case notes were not reviewed and no additional investigation was carried out, so as the quality of the incident reviews would be in line with the unit's Risk Management standards and process. This study is also limited by the single centre nature of 
the SUI reviews, although our unit is one of the largest tertiary centres in the UK with over 9,200 deliveries per year. However, as the quality of SUI reviews vary significantly between centres, using reviews within the same centre based on the same template ensured consistency in the process and findings. It is important to determine whether the findings of this study are replicated in other units which have implemented 24-7 consultant presence.

\section{Conclusion}

Introduction of 24-7 consultant presence significantly increased the consultant's involvement in managing obstetric emergencies, and cases which were subsequently deemed to be SUls. It also reduced the proportion of cases where a lack of, or delay in consultant presence was felt to have negative impact on maternal or neonatal outcome by SUI reviews. Consultant presence was more likely to have a positive influence on care delivery. This observation builds on data from a qualitative study in this research programme which demonstrates that midwives, doctors in training and consultants themselves perceived that 24-7 consultant obstetric presence prevented adverse outcomes, particularly given the high-risk nature of some of the caseload (Reid et al., 2018). However, further studies aiming to evaluate the effect of consultant presence on labour ward are still needed, particularly to determine whether 24-7 consultant presence does reduce the incidence of serious intrapartum complications. 


\section{References}

Heller, G., Misselwitz, B. \& Schmidt, S. (2000). Early neonatal mortality, asphyxia related deaths, and timing of low risk births in Hesse, Germany, 1990-8: observational study. $B M J$, Vol 321 No. 7256, Pp 274-5.

Henderson, J., Kurinczuk, J. J. \& Knight, M. (2017). Resident consultant obstetrician presence on the labour ward versus other models of consultant cover: a systematic review of intrapartum outcomes. BJOG, Vol 124 No. 9, Pp 1311-1320.

Luo, Z. C. \& Karlberg, J. (2001). Timing of birth and infant and early neonatal mortality in Sweden 1973-95: longitudinal birth register study. BMJ, Vol 323 No. 7325, Pp 132730 .

Mcnamara, K., Meaney, S. \& O'donoghue, K. (2018a). Intrapartum fetal death and doctors: a qualitative exploration. Acta Obstet Gynecol Scand, Vol No. Pp.

Mcnamara, K., O'donoghue, K. \& Greene, R. A. (2018b). Intrapartum fetal deaths and unexpected neonatal deaths in the Republic of Ireland: 2011 - 2014; a descriptive study. BMC Pregnancy Childbirth, Vol 18 No. 1, Pp 9.

National Health Service Resolution (2017). Annual report and accounts 2016/17.

National Health Service Letigation Authority (2013). Clinical Negligence Scheme for Trusts. Maternity. Clinical Risk Management Standards. National Health Service Litigation Authority.

National Patient Safety Agency (2008). A risk matrix for risk managers.

Pasupathy, D., Wood, A. M., Pell, J. P., Fleming, M. \& Smith, G. C. (2010). Time of birth and risk of neonatal death at term: retrospective cohort study. BMJ, Vol 341 No. Pp c3498.

Royal College of Obstetricians and Gynaecologists (2005). The future role of the consultant: a working party report. Royal College of Obstericians and Gynaecologists, London.

Royal College of Obstetricians and Gynaecologists (2007). Safer childbirth: minimum standards for the organisation and delivery of care in labour.: Royal College of Obstericians and Gynaecologists, London.

Royal College of Obstetricians and Gynaecologists (2016). Providing quality care for women: obstetrics and gynaecology workforce. Royal College of Obstetricians and Gynaecologists, London.

Reason, J. (2000). Human error: models and management. BMJ, Vol 320 No. 7237, Pp 76870.

Reid, H. E., Wittkowski, A., Vause, S. \& Heazell, A. E. P. (2018). 'Just an extra pair of hands'? A qualitative study of obstetric service users' and professionals' views towards 24/7 consultant presence on a single UK tertiary maternity unit. BMJ Open, Vol 8 No. 3 , Pp e019977.

Roach, V. (2016). 24-hour consultant labour ward cover should be mandatory in tertiary obstetric hospitals: AGAINST: 24-hour consultant presence doesn't enhance training and supervision of trainees. BJOG, Vol 123 No. 8, Pp 1379.

Ruffieux, C., Marazzi, A. \& Paccaud, F. (1992). The circadian rhythm of the perinatal mortality rate in Switzerland. Am J Epidemiol, Vol 135 No. 8, Pp 936-52.

Smith, G. C. (2016). The increased perinatal mortality rate over weekends is proof that we require a 7-day maternity service: AGAINST: Shifting resources towards delivery units and away from antenatal care could increase perinatal mortality. BJOG, Vol 123 No. 8, Pp 1359.

Snowden, J. M., Tilden, E. L. \& Caughey, A. B. (2016). The increased perinatal mortality rate over weekends is proof that we require a 7-day maternity service: FOR: No baby should die simply because they are born at a weekend. BJOG, Vol 123 No. 8, Pp 1358. 
Stewart, J. H., Andrews, J. \& Cartlidge, P. H. (1998). Numbers of deaths related to intrapartum asphyxia and timing of birth in all Wales perinatal survey, 1993-5. BMJ, Vol 316 No. 7132, Pp 657-60.

Walker, S. P. (2016). 24-hour consultant labour ward cover should be mandatory in tertiary obstetric hospitals: FOR: The presence of a fully trained obstetrician should be mandatory in tertiary obstetric hospitals. BJOG, Vol 123 No. 8, Pp 1378. 


\section{Figures Legends}

Figure 1: The impact of 24-7 consultant presence on the management of clinical untoward incidents. The incidents were classified into 1 of 5 categories. Category 1: The consultant was not involved in the management. Category 2: The consultant was involved but had neither a positive nor a negative effect on the outcome of the incident. Category 3: The consultant had an overall positive influence. Category 4: The consultant had an overall negative influence on the management of the incident. Category 5: The lack of, or delay in, consultant presence carried a negative impact on the outcome of the incident. 


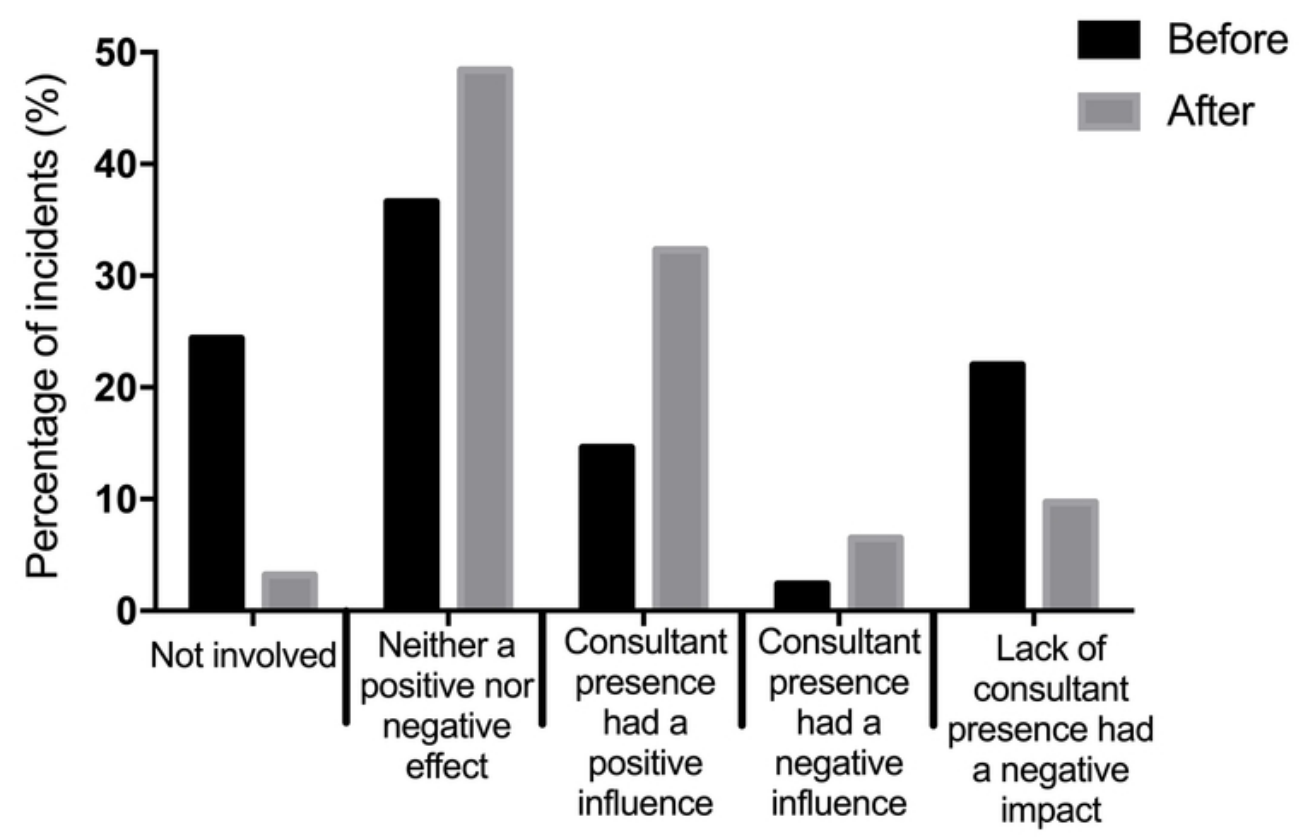

Figure 1: The impact of 24-7 consultant presence on the management of clinical untoward incidents. The incidents were classified into 1 of 5 categories. Category 1: The consultant was not involved in the management. Category 2: The consultant was involved but had neither a positive nor a negative effect on the outcome of the incident. Category 3: The consultant had an overall positive influence. Category 4: The consultant had an overall negative influence on the management of the incident. Category 5: The lack of, or delay in, consultant presence carried a negative impact on the outcome of the incident. 